\title{
A influência da precipitação na concentração e carga de sólidos em cursos d'água urbanos: o caso do arroio Dilúvio, Porto Alegre-RS
}

\author{
Luís Alberto Basso* \\ Luiza Gehrke Ryff Moreira, Fernanda Pizzato ${ }^{* *}$
}

\section{Resumo}

A bacia hidrográfica do arroio Dilúvio, situada em Porto Alegre-RS, é uma das mais urbanizadas da cidade, o que motiva um estudo que avalie as alterações das características presentes da água desse arroio durante evento pluviométrico elevado. $\mathrm{O}$ objetivo principal desse estudo é analisar a influência das chuvas na concentração de sólidos dissolvidos totais (SDT) e sólidos em suspensão totais (SST) no arroio Dilúvio, além de avaliar a carga exportada desses parâmetros para o lago Guaíba, onde o arroio desemboca. As coletas de água foram realizadas quando a precipitação foi maior que $20 \mathrm{~mm}$ e em dois momentos distintos: uma e quatro horas após o seu início. Os resultados indicaram aumento substancial na concentração de SST da primeira coleta para a segunda coleta, já em relação ao SDT ocorreu o contrário. A descarga sólida exportada pelo arroio no lago Guaíba variou de 9,3 toneladas por dia até aproximadamente 75,0 toneladas por dia.

Palavras-chave: Bacia hidrográfica; Urbanização; Precipitação; Sólidos em suspensão totais; Sólidos dissolvidos totais.

\footnotetext{
Professor do Departamento de Geografia do Instituto de Geociências da UFRGS (lbasso@ terra.com.br).

** Mestrandas do Programa de Pós-Graduação em Geografia da UFRGS (luizaryffmoreira@hotmail.com e fp1988@hotmail.com).
}

Geosul, Florianópolis, v. 26, n. 52, p 145-163, jul./dez. 2011 
BASSO, L.A. at al. A influência da precipitação na concentração e carga de...

The influence of precipitation on the concentration and load of solids in urban streams: the case of the Dilúvio stream, Porto Alegre-RS

\section{Abstract}

The Dilúvio stream watershed, set inside the municipality of Porto Alegre, the capital city of the southernmost Brazilian state, Rio Grande do Sul, is one of the most urbanized watershed within the city, promoting the study that evaluates the changes in water characteristics during great precipitation events. The main objective of this work was to analyze the influence of the rain on the concentration of total dissolved solids (TDS) and total suspended solids (TSS) in the Dilúvio stream, and also to evaluate the exported load of these parameters inflowing to the Guaíba Lake. Water sampling was held when the precipitation rose above $20 \mathrm{~mm}$, at two distinct times: one and four hours after the $20 \mathrm{~mm}$ mark. Results indicated a substantial increase in the TSS concentration from the first sampling to the second. As for the TDS, the concentrations showed the inverse relation. The exported solid discharge to the Guaíba Lake varied from 9.3 tons per day to approximately 75.0 tons per day.

Key words: Watershed; Urbanization; Precipitation; Total suspended solids; Total dissolved solids.

\section{Introdução}

A partir da segunda metade do século XX o processo de urbanização intensifica-se em países emergentes, como o Brasil, onde o crescimento dos centros urbanos se dá de maneira acelerada e desordenada, passando, assim, a manifestar diversos tipos de problemas socioambientais, muitos deles relacionados diretamente ao "inchaço populacional" e às ocupações irregulares em áreas de risco à inundação (ZANELLA, 2006). 
BASSO, L.A. at al. A influência da precipitação na concentração e carga de...

$\mathrm{O}$ crescimento populacional e de edificações em áreas urbanas geram maior impermeabilização do solo, facilitando o aumento do escoamento superficial e, assim, ocasionando impactos negativos ao ambiente, principalmente problemas de inundação urbana. As inundações são resultados não apenas do aumento do volume de precipitação, mas principalmente do aumento da velocidade do escoamento superficial decorrente tanto da impermeabilização do solo como da ampliação do sistema de microdrenagem (bueiros e tubulações secundárias) e macrodrenagem (conjunto de galerias de águas pluviais e canais artificiais). Em Porto Alegre, sul do Brasil, a quantidade de águas pluviais que alcança o arroio Dilúvio aumentou significativamente com o desenvolvimento urbano das últimas décadas. $\mathrm{O}$ volume de água que antes infiltrava no solo ou escoava lentamente sobre a superfície, com a impermeabilização provocada pelo asfalto, edificações e calçadas, alcança rapidamente o arroio, elevando a vazão e produzindo picos de enchentes em áreas localizadas mais a jusante da bacia hidrográfica. Além disso, essas águas que se direcionam ao curso fluvial carregam uma grande quantidade de sedimentos e outras substâncias oriundas da limpeza da cidade pela água das chuvas, contribuindo para a deterioração da qualidade da água e do assoreamento do arroio.

Rossato \& Silva (2004) alertam que o aumento na produção de sedimentos em bacias hidrográficas está estritamente relacionado aos processos de urbanização em regiões próximas, pois ela promove a alteração da cobertura do solo através da colocação de pavimentos impermeáveis e implantação de dutos subterrâneos de escoamento pluvial. Essas mudanças acarretam uma redução da infiltração do solo, aumentando o escoamento superficial. Esse aumento do volume e velocidade da água, associado à obstrução encontrada no caminho, gera inundações, que segundo eles, são cada vez mais frequentes na cidade de Porto Alegre.

Outros estudos focaram a relação entre urbanização e inundação. Pastorino (1971) analisou alguns aspectos do problema das inundações no espaço urbano/metropolitano de São Paulo, relacionando problemas de natureza hidrológica com as questões 
BASSO, L.A. at al. A influência da precipitação na concentração e carga de... relativas à urbanização desordenada nas planícies de inundação do setor paulistano da bacia do rio Tietê. Também, Paschoal (1981), direcionando sua análise para o bairro do Cambuci, na cidade de São Paulo, comprovou um aumento considerável do número de inundações nas décadas de 1960 e 1970. Entre o período de 1961/70, ocorreram 13 inundações, e entre 1971/78, 52. Esta autora apontou os problemas de urbanização da área e a precariedade dos serviços de infra-estrutura urbana como fatores importantes para a intensificação do problema, afetando a drenagem do rio Tamanduateí. No mesmo estudo, a autora analisou também a percepção das comunidades atingidas pelas inundações em referido bairro.

A sub-bacia hidrográfica do Dilúvio é uma das mais urbanizadas da capital gaúcha tendo uma densidade populacional de $6.417 \mathrm{hab} / \mathrm{km}^{2}$ (MENEGAT et al., 1998). Possui aproximadamente $81 \mathrm{~km}^{2}$, dos quais $83 \%$ estão em Porto Alegre e o restante situa-se no município vizinho de Viamão. O principal curso fluvial dessa sub-bacia é o Dilúvio cujas nascentes encontram-se no Parque Saint-Hilaire, localizado na divisa dos municípios de Porto Alegre e Viamão (Figura 1). Esta nascente do arroio é a parte mais limpa de todo seu curso, enquanto a sua foz no lago Guaíba, constitui o setor mais deteriorado do arroio. O Dilúvio percorre a céu aberto 10 bairros da cidade de Porto Alegre, altamente urbanizados e com grande densidade populacional, além da área pertencente ao município de Viamão. A parte canalizada do arroio possui aproximadamente $12 \mathrm{~km}$, sendo sua extensão total de aproximadamente $18 \mathrm{~km}$. O arroio recebe anualmente $50.000 \mathrm{~m}^{3}$ de sedimentos e lixo em suas águas, o que corresponde a 10.000 caminhões-caçamba cheios (DEP, 2011). Por isso, o Dilúvio e seus afluentes necessitam de limpeza e dragagem frequentes. Porém, conforme advertem Collischonn et al. (2001) a dragagem além de ser uma operação cara, exige área adequada para a deposição do material dragado, degrada as margens dos arroios e, muitas vezes interrompe o trânsito quando da retirada do material por parte de caminhões. 
BASSO, L.A. at al. A influência da precipitação na concentração e carga de...

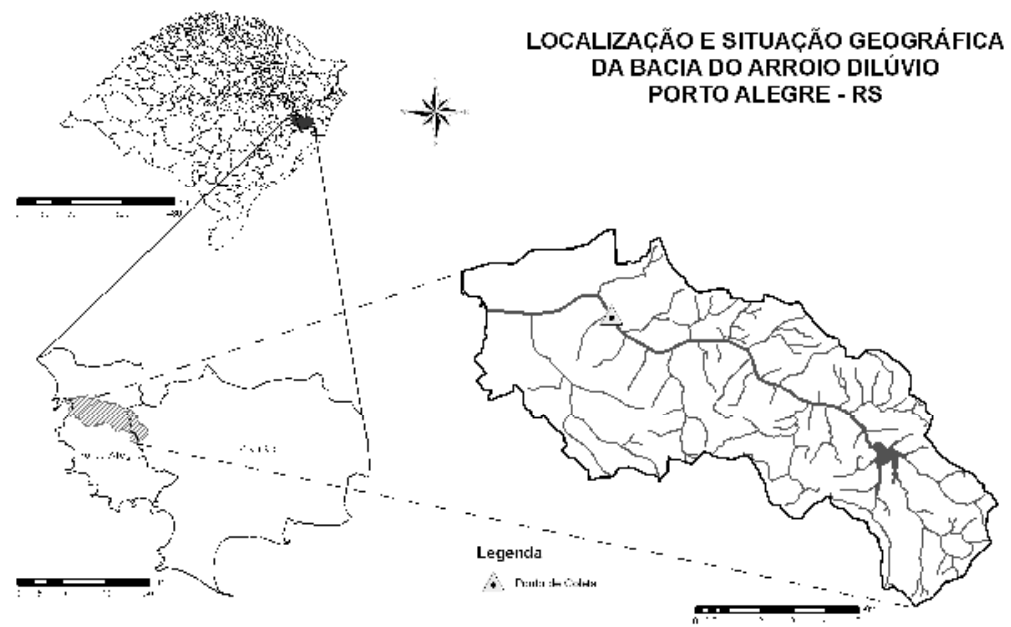

Figura 1: Localização e situação geográfica da bacia hidrográfica do arroio Dilúvio. (Elaborado por Michel Pinto de Almeida e Fernanda Pizzato)

Tucci (1995) alerta que o Dilúvio, devido a sua largura e pouca profundidade, em períodos de estiagem, apresenta setores com vegetação dentro do canal, a qual reduz sua capacidade para escoamento das águas em época de enchentes. Isso torna as áreas de entorno do arroio mais suscetíveis a alagamentos e inundações.

Em síntese os principais efeitos negativos da produção de sedimentos são: assoreamento da rede de drenagem, redução da capacidade de escoamento de condutos, rios e lagos urbanos e, consequentemente, maior frequência de extravasamentos. Outra importante consequência é o transporte de poluentes adsorvidos nas argilas presentes nos sedimentos, que contaminam as águas pluviais e, também, os cursos fluviais (COLLISCHONN et al., 2001).

Ramos (1995) salienta que há poucos dados sobre a produção de sedimentos em áreas urbanas, porém adverte sobre a 
BASSO, L.A. at al. A influência da precipitação na concentração e carga de... importância dos efeitos da urbanização sobre essa produção. Cita estudos norte-americanos sobre a variabilidade da produção de sedimentos que mostraram que as taxas máximas de transporte sólido nos eventos pluviométricos mais importantes durante o auge da urbanização foram cerca de 50 vezes o transporte sólido nas condições originais da bacia hidrográfica.

Paiva et al. (2001) realizaram monitoramento hidrossedimentométrico em bacia hidrográfica de $1,5 \mathrm{~km}^{2}$ no município de Santa Maria (RS) em processo de urbanização. Verificaram que a concentração de sedimentos apresentou um pico no início do evento pluviométrico, possivelmente correspondente à carga de lavagem das ruas, passando a seguir a variar de acordo com a vazão.

Outros estudos procuraram estudar a produção de sedimentos em áreas rurais. Pinto et al. (2009) estimaram a carga de sedimentos exportada pelo córrego Bom Jardim (MS) no rio Paraná, onde verificaram que o transporte de sedimentos foi maior no verão do que na estação do inverno. Lima et al. (2005) estudaram o fluxo de sedimentos em suspensão ao longo da bacia do rio Paranapanema (SP-PR). Constataram uma produção específica de sedimentos em suspensão que variou de baixa a moderada: de 13 a $77 \mathrm{t} / \mathrm{km}^{2} /$ ano.

O presente estudo visa analisar a influência das precipitações intensas sobre a concentração de sólidos dissolvidos totais (SDT) e sólidos em suspensão totais (SST) no principal curso fluvial da cidade de Porto Alegre, o arroio Dilúvio, assim como, avaliar a carga exportada desses parâmetros no Lago Guaíba.

A determinação da concentração assim como da carga exportada desses sólidos (dissolvidos e suspensos) é de extrema importância para a avaliação da qualidade das águas e do ambiente em geral, pois eles relacionam-se diretamente com a produção de sedimentos nos corpos d'água. Os sólidos suspensos na água possuem elevada superfície de contato, o que aumenta a capacidade de adsorção de elementos traços, ou seja, neles podem estar agregadas substâncias poluentes. A quantidade de material 
BASSO, L.A. at al. A influência da precipitação na concentração e carga de... suspenso prejudica não apenas a estética e a biota local, mas exerce influência em uma vasta área, dependendo das condições hidráulicas do corpo aquático. Assim, seus efeitos na vida aquática são indiretos, à medida que impedem a penetração de luz, reduzem o teor de oxigênio dissolvido e induzem ao aquecimento da água.

Sabe-se que os sólidos presentes nos cursos d'água podem ser originados através de processos erosivos naturais ou acelerados do solo, lançamento de efluentes domésticos e industriais, disposição de resíduos sólidos no ambiente carreados pelas chuvas através da drenagem superficial ou subterrânea, ou, ainda, devido às construções, abertura de ruas e limpeza de terrenos. Desta forma, constata-se que as principais fontes de sólidos nas águas estão associadas à intervenção humana no ambiente.

\section{Material e métodos}

O conhecimento sobre o comportamento da pluviometria e da concentração de parâmetros como os sólidos dissolvidos e em suspensão em cursos fluviais é fundamental para avaliar a carga de sólidos exportada pelo Dilúvio ao Guaíba.

De maneira geral o trabalho consistiu em realizar saídas de campo para coletar amostras de água no arroio Dilúvio, durante eventos pluviométricos intensos. Logo após a finalização das coletas, as amostras foram enviadas ao laboratório para determinação das concentrações de SDT e SST. Levando-se em conta o dado da vazão média do arroio e de posse dos valores das concentrações dos parâmetros, calculou-se a descarga sólida total exportada para o lago Guaíba pelo Dilúvio.

A definição do ponto de coleta das amostras, localizado na Avenida Ipiranga esquina com a Rua Lucas de Oliveira, considerou a existência no local de um limnígrafo que registra a vazão do córrego, pois a mesma é fundamental para a estimativa da descarga sólida.

Realizou-se uma análise pluviométrica dos dias em que foram feitas as coletas através de dados de precipitação coletados 
BASSO, L.A. at al. A influência da precipitação na concentração e carga de... no Oitavo Distrito de Meteorologia de Porto Alegre, órgão que possui uma estação meteorológica situada a menos de $3 \mathrm{~km}$ do local das coletas

As amostragens foram feitas quando da ocorrência de um evento pluviométrico intenso, ou seja, nas ocasiões em que a precipitação alcançou $20 \mathrm{~mm}$ num pequeno intervalo de tempo. As amostras foram coletadas no centro do canal, manualmente, com auxílio de balde plástico e, acondicionadas, em frascos adequados à determinação da concentração de SDT e SST. As coletas foram realizadas nos dias 11/09/2008, 14/10/2008, 12/05/2009, 17/08/2009 e 01/10/2009 em duas ocasiões distintas: uma hora após o início da precipitação e quatro horas após o início da mesma, o que possibilitou perceber as diferenças das concentrações em dois momentos diferenciados do evento pluviométrico. Também, realizou-se em 24/03/2009 uma coleta de amostra em época "normal", ou seja, em período sem chuva, para posteriormente comparar os dados das coletas com a situação "normal".

As análises dos parâmetros, sólidos dissolvidos totais (SDT) e sólidos em suspensão totais (SST) foram realizadas no Centro de Ecologia (CENECO) da Universidade Federal do Rio Grande do Sul (UFRGS), sendo utilizado o método gravimétrico. Este laboratório utiliza como referência de análise as normas técnicas da Standard Methods $21^{\text {st }}$ (APHA, 2005) assumindo-se que o conteúdo total de sólidos de uma amostra de água é definido como toda matéria que permanece como resíduo após evaporação à temperatura de 103 a $105{ }^{\circ} \mathrm{C}$. O material que possui significativa pressão de vapor nessa temperatura é perdido durante a evaporação e não é definido como sólido. Do conteúdo total de sólidos podemse diferenciar dois subgrupos de acordo com o tamanho das partículas sólidas. Os sólidos em suspensão (SST, partículas com diâmetro superior a 1 ) e sólidos filtráveis (SDT, dissolvidos mais coloidais). Os sólidos em suspensão são aqueles retidos por filtração com uma membrana de porosidade específica, sendo os 
BASSO, L.A. at al. A influência da precipitação na concentração e carga de... sólidos filtráveis os não retidos. Os sólidos filtráveis compreendem as partículas dissolvidas e as em estado coloidal.

A partir dos dados de vazão fornecidos pelo órgão responsável pelas medições no arroio Dilúvio, a Companhia de Pesquisa e Recursos Minerais (CPRM), e da concentração dos parâmetros encontrados nas amostras de água, foi possível calcular o transporte diário de material sólido em suspensão e dissolvido para o lago Guaíba.

A descarga ou transporte diário do material dissolvido e em suspensão foi calculado através do produto da vazão pela concentração diária das variáveis SDT e SST, a partir da equação (CONTE \& LEOPOLDO, 2001):

$$
\mathrm{Q}_{\mathrm{x}}=\mathrm{K} \times \mathrm{Q} \times \mathrm{C}
$$

Nesta equação $\mathrm{Q}_{\mathrm{x}}$ corresponde a descarga sólida, $\mathrm{K}$ é uma constante que envolve transformação de unidades $(0,0864)$, Q é a vazão líquida expressa em $\mathrm{m}^{3} \mathrm{~s}^{-1}$ e $\mathrm{C}$ é a concentração da variável em $\mathrm{mg} \mathrm{L}^{-1}$, ou seja, dos sólidos. O resultado é fornecido em toneladas dia ${ }^{1}$.

\section{Resultado e discussão}

A Figura 2 apresenta a pluviometria diária do período de realização do estudo, assim como as datas de coleta das amostras. Percebe-se a grande variabilidade da precipitação na bacia do Dilúvio, com valores máximos próximos de $74 \mathrm{~mm}$ em 24 horas. Outro dado interessante é que no intervalo de 396 dias de dados pluviométricos diários, a chuva superou a marca dos $20 \mathrm{~mm}$ diários em 33 dias, o que representa $8,3 \%$.

No dia 11/09/2008 choveu 45,6 mm, no dia 14/10/2008 a precipitação alcançou $27,8 \mathrm{~mm}$, em 12/05/2009 a chuva chegou a $20,4 \mathrm{~mm}$ e no dia 17/08/2009 atingiu $31 \mathrm{~mm}$. Nesses quatro dias de realização de coletas choveu acima de $20 \mathrm{~mm}$. Na data da última amostragem, dia 01/10/2009 foi realizada apenas a primeira coleta, já que a chuva não continuou, alcançando apenas $12 \mathrm{~mm}$. O gráfico 
BASSO, L.A. at al. A influência da precipitação na concentração e carga de... mostra também que no dia 24/03/2009 fez-se uma coleta em período de "tempo seco", com o objetivo de comparar a concentração dos parâmetros em dias de chuva com esse dado que reflete a condição "seca".

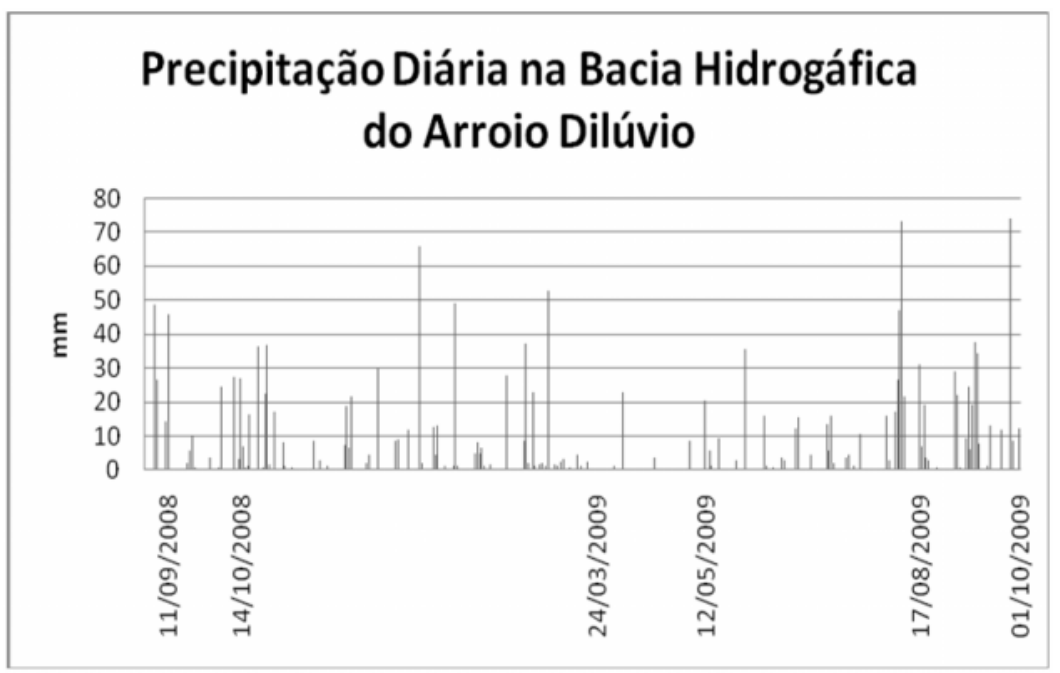

Figura 2: Precipitação diária na bacia hidrográfica do arroio Dilúvio.

No dia 11/09/08 a chuva iniciou por volta das 8 horas da manhã e a primeira coleta foi realizada às 9 horas da manhã, seguindo a metodologia que estabelecia a primeira coleta de amostra de água após uma hora do início da precipitação. A segunda coleta foi realizada ao meio-dia, ou seja, quatro horas após o início da precipitação.

Já em 14/10/2008 a precipitação não foi tão elevada quanto à anterior, embora tenha atingido um total de $26,4 \mathrm{~mm}$. Os horários das coletas no mês de outubro foram semelhantes aos de setembro. A precipitação iniciou por volta das $7 \mathrm{~h} 30 \mathrm{~min}$ da manhã e a primeira coleta foi feita às $8 \mathrm{~h} 30 \mathrm{~min}$. Já, a segunda coleta do dia 
BASSO, L.A. at al. A influência da precipitação na concentração e carga de... foi feita em torno das $11 \mathrm{~h} 30 \mathrm{~min}$ da manhã, quatro horas após o início da precipitação.

No dia 12/05/2009 a primeira coleta foi realizada às $10 \mathrm{~h}$ e a segunda coleta às $13 \mathrm{~h}$. No dia 17/08/2009 a primeira coleta foi feita às 8 h e a segunda coleta às 11 h. Já, no dia 01/10/2009 a primeira e única coleta foi feita às $8 \mathrm{~h}$.

O Quadro 1 apresenta os resultados das concentrações dos parâmetros analisados SDT e SST, a pluviometria acumulada e a vazão no momento da coleta das amostras. As amostras 1 referemse a coletas realizadas uma hora após o início da precipitação e as amostras 2 correspondem às coletas de quatro horas após o início da precipitação. Também, se indica os mesmos dados para a data de 24/03/2009, correspondente a um período seco, portanto sem influência da água da chuva nos parâmetros.

\begin{tabular}{|c|c|c|c|c|c|c|}
\hline Data & Amostra & SDT $\left(\mathrm{mg} \mathrm{L}^{-1}\right)$ & SST $\left(\mathrm{mg} \mathrm{L}^{-1}\right)$ & $\begin{array}{c}\text { Sólidos Totais } \\
\left(\mathrm{mg} \mathrm{L}^{-1}\right)\end{array}$ & $\begin{array}{c}\text { Precipitação } \\
(\mathrm{mm})\end{array}$ & $\begin{array}{c}\text { Vazão } \\
\left(\mathrm{m}^{3} \mathrm{~s}^{-1}\right)\end{array}$ \\
\hline \multirow{2}{*}{$11 / 09 / 2008$} & 1 & 70 & 32 & 102 & 3,6 & 7,0 \\
\cline { 2 - 7 } & 2 & 54 & 420 & 474 & 24,4 & 8,5 \\
\hline \multirow{2}{*}{$14 / 10 / 2008$} & 1 & 207 & 30 & 237 & 2,2 & 5,4 \\
\cline { 2 - 7 } & 2 & 126 & 578 & 704 & 23,6 & 8,5 \\
\hline \multirow{2}{*}{$12 / 05 / 2009$} & 1 & 128 & 526 & 654 & 7,4 & 4,0 \\
\cline { 2 - 7 } & 2 & 220 & 604 & 824 & 20,4 & 16,0 \\
\hline \multirow{2}{*}{$17 / 08 / 2009$} & 1 & 208 & 100 & 308 & 2,6 & 16,0 \\
\cline { 2 - 7 } & 2 & 108 & 228 & 336 & 21,6 & 17,0 \\
\hline $01 / 10 / 2009$ & 1 & 158 & 73 & 231 & 5,0 & 3,8 \\
\hline \multirow{2}{*}{$24 / 03 / 2009$} & $\begin{array}{c}\text { Período } \\
\text { seco }\end{array}$ & 187 & 13 & 200 & - & 0,5 \\
\hline
\end{tabular}

Quadro 1: Concentração de sólidos dissolvidos, em suspensão e totais; pluviometria e vazão no arroio Dilúvio.

A partir da análise dos dados do Quadro 1 verifica-se a grande variação da concentração de SST e sólidos totais nas amostras coletadas. As concentrações variaram de $30 \mathrm{mg} \mathrm{L}^{-1}$ a 604 mg L ${ }^{-1}$ para SST e de $102 \mathrm{mg} \mathrm{L}^{-1}$ a $824 \mathrm{mg} \mathrm{L}^{-1}$ para os sólidos totais, o que representa uma variação de $1913 \%$ e $708 \%$, respectivamente. Já a amplitude dos valores de SDT foi menor: de $54 \mathrm{mg} \mathrm{L}^{-1}$ a $220 \mathrm{mg} \mathrm{L}^{-1}$, o que representa $307 \%$ de variação. Essa 
BASSO, L.A. at al. A influência da precipitação na concentração e carga de... variação na concentração desses parâmetros decorre fundamentalmente das precipitações que exercem ora papel de diluição de poluentes, ora de arraste de material e sedimentos.

Morandi \& Faria (2000) em estudo sobre a qualidade da água do arroio Dilúvio detectaram teores médios de SDT entre 171 $\mathrm{mg} \mathrm{L}^{-1}$ e $188 \mathrm{mg} \mathrm{L}^{-1}$, e valor máximo de $282 \mathrm{mg} \mathrm{L}^{-1}$, demonstrando pequena variação da concentração deste parâmetro em oito estações de amostragem ao longo do arroio, indo de encontro ao dado obtido no presente estudo na campanha de 24/03/2009: única coleta de amostra de água em período longo de tempo seco, na qual a concentração de SDT foi de $187 \mathrm{mg} \mathrm{L}^{-1}$, e as de SST e sólidos totais foram de $13 \mathrm{mg} \mathrm{L}^{-1}$ e $200 \mathrm{mg} \mathrm{L}^{-1}$, respectivamente.

Em quase todas as campanhas de amostragens as concentrações de SDT diminuíram da primeira para a segunda coleta, variando essa diminuição de $23 \%$ a $48 \%$. Isso significa que as chuvas têm efeito diluidor para o SDT, ou seja, com o aumento da vazão há redução na concentração de SDT. Exceção feita à campanha realizada em maio de 2009, quando houve elevação na concentração de SDT, da primeira para a segunda coleta, aumento, este, em torno de $72 \%$.

Em relação ao comportamento de SST, percebe-se que esse parâmetro sempre aumentou a sua concentração da primeira para a segunda coleta. Esses aumentos foram significativos: variaram de $15 \%$ a $1827 \%$. Concentrações que rondavam $30 \mathrm{mg} \mathrm{L}^{-1}$ após uma hora de chuva, passaram a quase $580 \mathrm{mg} \mathrm{L}^{-1}$ depois de quatro horas do início da precipitação. Porém, na coleta do dia 12/05/2009 observa-se um aumento menor na concentração de SST da primeira para a segunda amostra, pois na primeira hora de precipitação já havia chovido quase $7,5 \mathrm{~mm}$, valor bem maior que o das demais campanhas. Ou seja, a intensidade da chuva na campanha de maio de 2009 foi suficiente para arrastar grande quantidade de SST (526 $\mathrm{mg} \mathrm{L}^{-1}$ ) já na primeira hora do evento. Também pode contribuir para isso o fato que no período anterior a essa campanha choveu muito pouco e, assim, quando da precipitação do dia 12/05 ocorreu 
BASSO, L.A. at al. A influência da precipitação na concentração e carga de... uma maior lavagem das superfícies e dos solos a partir dessa enxurrada.

Outro aspecto importante do presente estudo foi estimar a carga exportada de sólidos em direção ao Lago Guaíba. A Figura 3 apresenta os valores obtidos na produção de sedimentos ou carga sólida exportada pelo arroio Dilúvio.

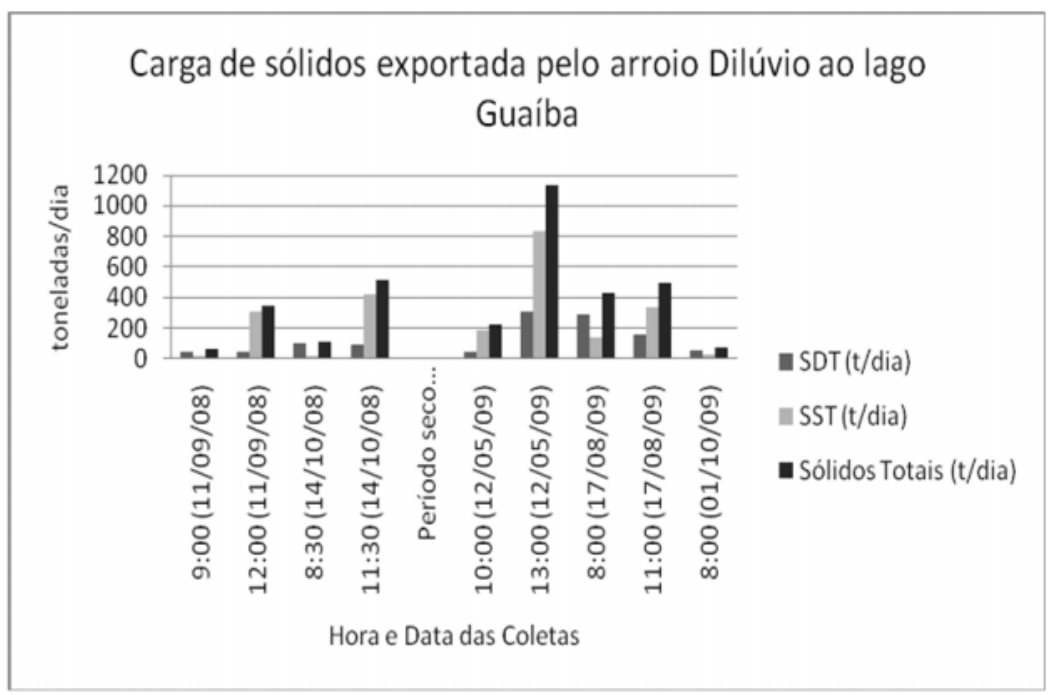

Figura 3: Carga de sólidos exportada pelo arroio Dilúvio ao lago Guaíba

Os dados da Figura 3 mostram que a carga de sólidos totais exportada pelo arroio Dilúvio para o lago Guaíba sempre aumentou da primeira para a segunda amostragem do dia. Isso se deve ao aumento da precipitação entre a primeira e a segunda coleta, que influencia na vazão do arroio. $\mathrm{O}$ incremento das chuvas entre as duas amostragens impulsiona a lavagem do solo e, consequentemente, a um maior carreamento de sedimentos para o arroio. Sabe-se que as obras civis em geral juntamente com os sistemas de drenagem são as grandes fontes de sedimentos em bacias urbanizadas como a do Dilúvio. 
BASSO, L.A. at al. A influência da precipitação na concentração e carga de...

A análise dos dados mostra que no dia 11/09/2008 houve elevação substancial na exportação de SST da primeira para a segunda amostragem: em torno de 16 vezes maior. Isso se deve ao incremento tanto da concentração de SST como da vazão, que por sua vez decorre da elevação da precipitação que alcançou $24,4 \mathrm{~mm}$ no momento da segunda amostragem. O aumento da quantidade da chuva num período de 3 horas (de 3,6 $\mathrm{mm}$ para 24,4 $\mathrm{mm}$ ) elevou em cerca de $1590 \%$ o valor exportado de SST ao Guaíba, evidenciando o poder de carreamento de uma grande quantidade de sedimentos para o arroio em função do aumento da precipitação. Também em 14/10/2008 houve aumento da precipitação que passou de 2,2 $\mathrm{mm}$ na primeira para $23,6 \mathrm{~mm}$ na segunda coleta do dia. Isso corresponde a um aumento da carga de 30 vezes: $14 \mathrm{t} / \mathrm{dia}$ às $8 \mathrm{~h} 30 \mathrm{~min}$ para $424 \mathrm{t} /$ dia três horas depois. Nas demais datas das coletas (12/05/2009 e 17/08/2009) ocorreu o mesmo fato: aumento da exportação de SST da primeira coleta para a segunda em função do incremento da precipitação/vazão do arroio e da concentração do parâmetro, porém essa elevação da carga foi menor que nas amostragens anteriores: 6 vezes em 12/05/2009 e 2,4 vezes em $17 / 08 / 2009$. Os dados revelam o poder das precipitações em arrastar grandes quantidades de partículas finas e outros resíduos que se traduzem na elevação das concentrações de SST nas águas do Dilúvio.

Em relação ao SDT percebe-se que em todas as campanhas, exceto na de maio de 2009 houve diminuição da carga exportada, pois as concentrações do parâmetro diminuíram da primeira para a segunda coleta, evidenciando o poder de diluição da água da chuva sobre esse parâmetro.

Quanto aos sólidos totais, os números impressionam. Em período "seco" foi exportado 8,6 t/dia ao lago Guaíba. Com a ocorrência das precipitações, os valores alcançaram 1.139 t/dia (maio de 2009), quando a concentração de sólidos totais foi de 824 $\mathrm{mg} \mathrm{L}^{-1}$ e a vazão atingiu $16 \mathrm{~m}^{3} \mathrm{~s}^{-1}$ ou $16.000 \mathrm{~L} \mathrm{~s}^{-1}$ no momento da segunda coleta. 
BASSO, L.A. at al. A influência da precipitação na concentração e carga de...

Segundo Lima et al. (2005) a concentração de sólidos em suspensão e de sólidos dissolvidos transmite uma importante informação sobre o curso d'água. Um rio com alta concentração de sedimentos é comumente denominado um rio "barrento". A elevada concentração de sedimentos na fonte hídrica pode trazer problemas aos sistemas de captação e tratamento de água, bem como aos reservatórios e aos sistemas de geração hidrelétrica.

A diferença do volume de água do Dilúvio no mesmo dia, entre a primeira e a segunda coleta, é evidenciada a partir da Figura 4. A vazão do arroio uma hora após o início da precipitação e depois de quatro horas do início é bem diferente. Durante os episódios verificados de intensa precipitação, a altura das águas do arroio Dilúvio aumentou, ou seja, a sua vazão teve acréscimo significativo devido, principalmente, à contribuição do sistema de drenagem. Nesse sentido, Tassi \& Poleto (2010) afirmam que a introdução de bocas-de-lobo, sarjetas, tubulações e galerias constituem um eficiente sistema de coleta e transporte do escoamento pluvial. Além de promover o escoamento com rapidez, os sistemas de drenagem também contribuem à deterioração da qualidade da água, pois carregam consigo uma enormidade de poluentes.

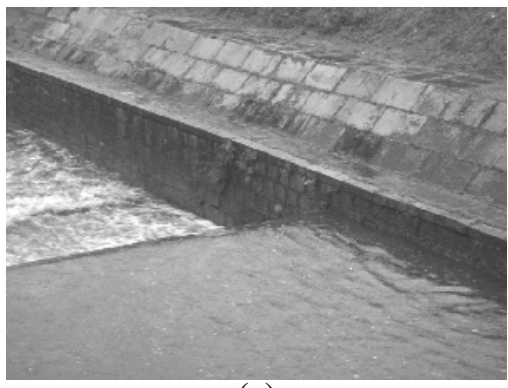

(a)

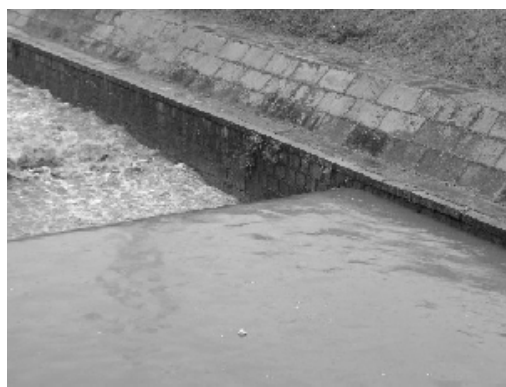

(b)

Figura 4: Vazão do arroio Dilúvio em 14/10/08 em dois horários distintos: (a) às $8 \mathrm{~h} 30 \mathrm{~min} \mathrm{e}(\mathrm{b})$ às $11 \mathrm{~h}$ 30min. 
BASSO, L.A. at al. A influência da precipitação na concentração e carga de...

Em síntese, os resultados obtidos pelo presente estudo, evidenciaram que o aumento progressivo da precipitação em área intensamente urbanizada - com canalizações de cursos d'água e presença de canais artificiais e galerias - incrementou o transporte de sólidos totais em um período de três horas de forte precipitação. As fortes chuvas arrastaram para o leito do Dilúvio sedimentos e detritos captados pela rede pluvial e cloacal. Observou-se, também, lixo e outros tipos de resíduos, que quando alcançam o arroio originam formas deposicionais bastante heterogêneas, algumas delas inclusive servindo de sustentação para vegetais que se desenvolvem ao longo do canal. Importante destacar que esses sedimentos estão, em sua grande maioria, impregnados de metais pesados e outros poluentes, contribuindo à contaminação e assoreamento do já bastante degradado arroio Dilúvio.

\section{Conclusão}

Os dados da pesquisa permitem concluir que há relação evidente entre a quantidade de precipitação e a concentração de sólidos dissolvidos totais e sólidos em suspensão totais no arroio Dilúvio. Em bacias hidrográficas fortemente urbanizadas (bem pavimentadas e com superfícies lisas) e com rede de drenagem pluvial "eficiente" como a do Dilúvio, quando da ocorrência de eventos pluviométricos expressivos, há um aporte significativo de material sólido que contribui para o assoreamento e deterioração da qualidade da água. Muitos desses sedimentos contêm partículas orgânicas e inorgânicas, além de elementos tóxicos como os metais pesados, que são lançados no Dilúvio e, consequentemente, alcançam o Guaíba, de onde a cidade de Porto Alegre retira água para o seu abastecimento, contribuindo também para a contaminação do lago.

Nesse sentido, o estudo foi importante porque comprovou a importância do monitoramento de sólidos dissolvidos totais e sólidos em suspensão totais, parâmetros fundamentais para analisar a carga exportada de sólidos ao sistema receptor, no caso o lago 
BASSO, L.A. at al. A influência da precipitação na concentração e carga de...

Guaíba. O conhecimento da carga transportada de sólidos ao longo do arroio fornecerá subsídios importantes ao gerenciamento municipal, em especial, aos planos e programas de drenagem urbanos que visam prevenir o assoreamento e a contaminação das águas do Dilúvio e do Guaíba.

\section{Referências bibliográficas}

AMERICAN PUBLIC HEALTH ASSOCIATION. Standard Methods for the Examination of Water and Wastewater. $21^{\text {st }}$ Edition. Washington, APHA, AWWA, WEF, 2005.

COLLISCHONN, W.; SEMMELMANN, F. R.; ROCKENBACH, C. A. Drenagem urbana e sedimentos: o caso do Arroio Dilúvio. In: Tucci, C. E. M.; Marques, D. M. (Orgs.). Avaliação e controle da drenagem urbana. Porto Alegre: Ed da UFRGS/ABRH, 2001. p. 521-548.

CONTE, M.L. \& LEOPOLDO, P.R.. Avaliação de recursos hídricos: rio Pardo, um exemplo. São Paulo: Editora UNESP, 2001, 141 p.

PREFEITURA MUNICIPAL DE PORTO ALEGRE. Departamento de Esgotos Pluviais. Disponível em: <http://www2.portoalegre.rs.gov.br/dep/default.php?p_secao=71>. Acesso em: 06 janeiro 2011.

LIMA, J. E. F.; LOPES, W. T. A.; SILVA, E. M. \& VIEIRA, M. R. Diagnóstico do fluxo de sedimentos em suspensão na bacia de Rio Paranapanema. In: XVI SIMPÓSIO BRASILEIRO DE RECURSOS HÍDRICOS, 2005. João Pessoa. Anais... João Pessoa ABES, 2005. 
BASSO, L.A. at al. A influência da precipitação na concentração e carga de... MENEGAT, R.; PORTO, M.L.; CARRARO, C.C.; FERNANDES, L.A.D. (Coords.). Atlas Ambiental de Porto Alegre. Porto Alegre: Editora da UFRGS, 1998.

MORANDI, I. C. \& FARIA, C. M. A. Difícil Recuperação de Arroios em áreas urbanas - Arroio Dilúvio - Porto Alegre - RS. In: CONGRESSO INTERAMERICANO DE ENGENHARIA SANITÁRIA E AMBIENTAL, XXVII, 2000. Porto Alegre. Anais... Porto Alegre: ABES, 2000. 1-14p. (CD-ROM).

PAIVA, E.M.C.D.; PAIVA, J.B.D.; COSTAS, M.F.T.; SANTOS, F.A. Concentração de sedimentos em suspensão em uma pequena bacia hidrográfica em urbanização. In: $21^{\circ}$ CONGRESSO BRASILEIRO DE ENGENHARIA SANITÁRIA E AMBIENTAL, 2001. João Pessoa. Anais...João Pessoa: ABES, 2001. 1-11p (CD-ROM).

PASCHOAL, W. As inundações no Cambuci: percepção e reação do habitante e usuário de uma área central da metrópole a um de seus problemas mais sérios. Dissertação (Mestrado) Departamento de Geografia, Universidade de São Paulo. São Paulo, 1981.

PASTORINO, L.A. O problema das enchentes na Região de São Paulo. Caderno de Ciências da Terra, São Paulo, n.19, Instituto de Geografia, USP, 1971.

PINTO, A.L.; OLIVEIRA, G.H.; PEREIRA, G. A. A influência do aporte de sedimentos fluviais na qualidade das águas superficiais da bacia do córrego Bom Jardim, Brasilândia/MS. In: II SEMINÁRIO DE RECURSOS HÍDRICOS DA BACIA HIDROGRÁFICA DO PARAÍBA DO SUL: RECUPERAÇÃO DE ÁREAS DEGRADADAS, SERVIÇOS AMBIENTAIS E SUSTENTABILIDADE, 2009. Taubaté, SP, Anais... Taubaté IPABHi, 09-11 dezembro 2009, p. 189-198. 
BASSO, L.A. at al. A influência da precipitação na concentração e carga de... RAMOS, C.L. Erosão urbana e produção de sedimentos. In: Tucci, C. E. M., Porto, R. L. e Barros, M. T. (Orgs.). Drenagem Urbana. Porto Alegre: Ed. da UFRGS/ABRH, 1995. p.241-275.

ROSSATO, M. S. \& SILVA, D. L. M. A reconstrução da paisagem metropolitana de Porto Alegre: o tempo do homem e a degradação ambiental da cidade. In: VERDUM, R, BASSO, L.A., SUERTEGARAY, D.M.A. (Orgs.). Rio Grande do Sul: paisagens e territórios em transformação. Porto Alegre: Ed. da UFRGS, 2004. p.107-124.

TASSI, R. \& POLETO, C. Gerenciamento integrado de bacias urbanas. In: POLETO, C. (Org.). Introdução ao Gerenciamento Ambiental. Rio de Janeiro: Interciência, 2010. p.22-44.

TUCCI, C.E.M. Inundações urbanas. In: TUCCI, C. E. M.; PORTO, R. L. L. \& BARROS, M. T.(Orgs.) Drenagem Urbana. Porto Alegre: Editora da UFRGS/ABRH, 1995. p.15-36.

ZANELLA, M. E. Eventos pluviométricos intensos e impactos gerados na cidade de Curitiba/PR - Bairro Cajuru: Um destaque para as inundações urbanas. Revista de Geografia da Universidade Federal do Ceará, Fortaleza, ano 05, número 09, 2006.

Recebido em março de 2011

Aceito em junho de 2012 